\title{
Revisão de dismorfia mamária com implantes pós- mastectomia subcutânea bilateral: relato de caso
}

\author{
Revision of breast dysmorphy with implants after subcutaneous bilateral \\ mastectomy: case report
}

Luciano Alves da Silva ${ }^{1}$ JOÃO RiCARDO DE BARROS

DIAS $^{2}$

Trabalho realizado no Hospital Santa Joana, Recife, PE, Brasil.

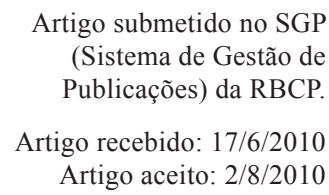

\begin{abstract}
RESUMO
Introdução: Mamas com implantes submetidas a adenomastectomia apresentam com frequência dismorfias estéticas secundárias, que exigem revisões cirúrgicas. Os autores enfatizam a importância do planejamento cirúrgico pré-operatório, para reduzir ou mesmo evitar comprometimento estético a médio e longo prazo. Objetivo: Relatar a conduta utilizada em um caso de adenomastectomia bilateral com implantes de silicone, seguida de alterações secundárias de forma, volume e simetria.
\end{abstract}

Descritores: Mastectomia. Implante mamário. Complicações pós-operatórias.

\begin{abstract}
Background: Breasts with silicone implants after subcutaneous mastectomy frequently present secondary aesthetic dysmorphies that request surgical revision. Purpose: The authors report and register the importance of a correct pre-operative surgical program to reduce and even avoid secondary aesthetic problems in mediate and long term postoperative period.
\end{abstract}

Keywords: Mastectomy. Breast implantation. Postoperative complications.

\section{INTRODUÇÃO}

O emprego de próteses de silicone nas reconstruções mamárias pós-adenomastectomias tem sido considerado uma das melhores opções por parte dos cirurgiões e das pacientes, pela maior facilidade de realização e pela qualidade dos resultados estéticos. Estes procedimentos são aplicados de rotina no mesmo ou em tempos operatórios diversos ${ }^{1-4}$.

A incidência de problemas e intercorrências no pósoperatório imediato e mesmo tardio, como hematoma, seroma, infecção, assimetrias e deslocamentos das próteses, além dos diversos graus de contratura, é semelhante aos demais procedimentos cirúrgicos.

\section{RELATO DO CASO}

Paciente caucasiana, nulípara, de 48 anos de idade, foi submetida a adenomastectomia bilateral em junho de 2001, por múltiplos adenomas, sem a reconstrução das mamas no mesmo tempo operatório. Sete meses após (janeiro 2002) foi submetida a reconstrução bilateral das mamas com implantes mamários de silicone, perfil alto de $230 \mathrm{ml}$, pela via periareolar inferior e em posição subglandular (Figura 1).

Em junho de 2002, novamente foi submetida a mastopexia pela técnica de Pitanguy na mama esquerda, não sendo tocada a mama direita. Dezoito meses depois, foi atendida no nosso consultório apresentando forte contratura capsular (Grau IV de Baker ${ }^{5,6}$ ), com grande retração mais evidente nos quadrantes inferiores da mama direita e assimetria inaceitável de forma e volume, com a prótese "ancorada" nos quadrantes superiores. Presença ainda de uma pequena brida cutânea no quadrante ínfero-esquerdo da mama direita (Figura 2).

\section{Técnica Cirúrgica}

Demarcação cutânea nas regiões mamárias com a paciente em posição ereta e previamente à medicação pré-anestésica, numa área além dos limites da contratura capsular (Figura 3). Cirurgia realizada sob anestesia geral, com intubação endotraqueal e infiltração cutânea peri-mamária com xilocaína a

1. Cirurgião plástico, Membro Titular da Sociedade Brasileira de Cirurgia Plástica (SBCP).

2. Cirurgião plástico, Membro Associado da SBCP. 

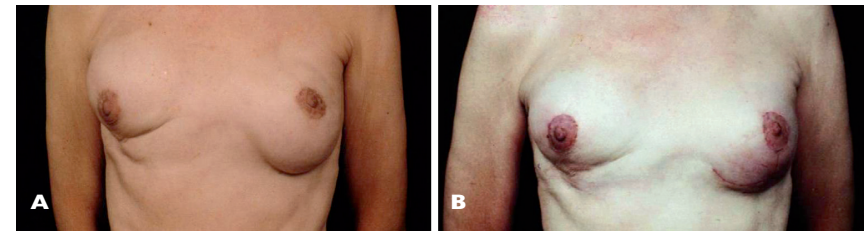

Figura 1 - Pré-operatório e pós-operatório do primeiro procedimento cirúrgico.
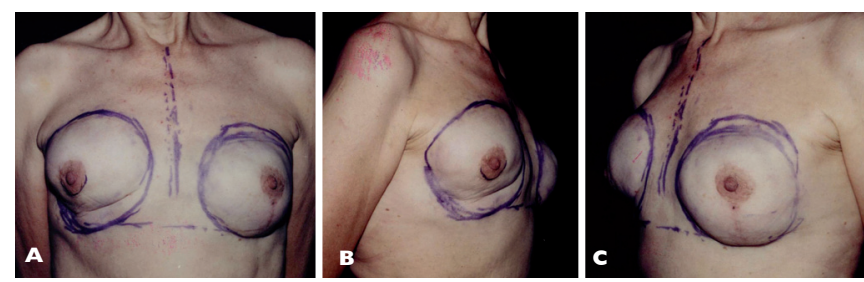

Figura 3 - Demarcação e plano de cirurgia para o terceiro procedimento.
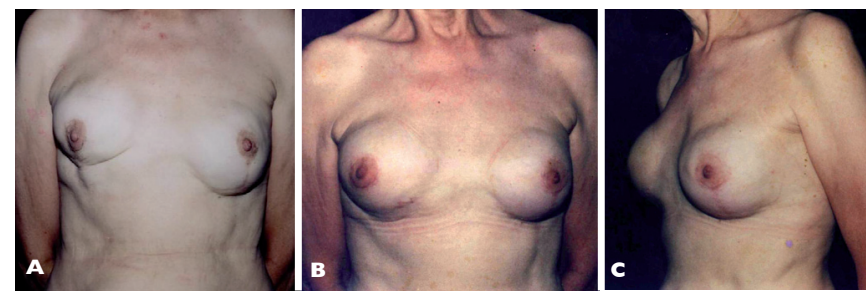

Figura 5 - Comparação entre o pré-operatório (A) e pósoperatório de um ano e seis meses ( $B$ e $C$ ).

$2 \%$ sem adrenalina e epinefrina a 1:500.000. Via de acesso peri-areolar inferior com a retirada das próteses bilateralmente. Dissecação da bolsa cutânea dentro dos limites estabelecidos na demarcação cutânea bilateralmente, particularmente nos quadrantes inferiores na mama direita e nos quadrantes superiores na mama esquerda. Hemostasia minuciosa. Implantes do tipo redondo, texturizado, perfil alto de $295 \mathrm{ml}$ (Silimed). Zetaplastia transfixante na área de aderência cutânea no quadrante ínfero externo da mama direita. Sutura por planos na via de acesso peri-areolar, com pontos isolados de Vicryl 3-0. Curativo compressivo com gaze, algodão e faixa de crepom.

\section{DISCUSSÃO}

Cápsulas do tipo III e IV de Baker a médio e longo prazo são frequentes após mastectomias subcutâneas. Fatores múltiplos intervêm direta e indiretamente em função das reações inerentes aos tipos das próteses, reações específicas das pacientes e, ainda, pelas manipulações dos cirurgiões. Os procedimentos têm por finalidade a restauração da estética
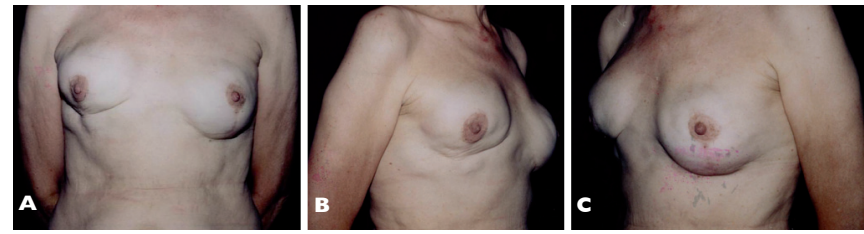

Figura 2 - Contratura severa bilateral após o primeiro procedimento.
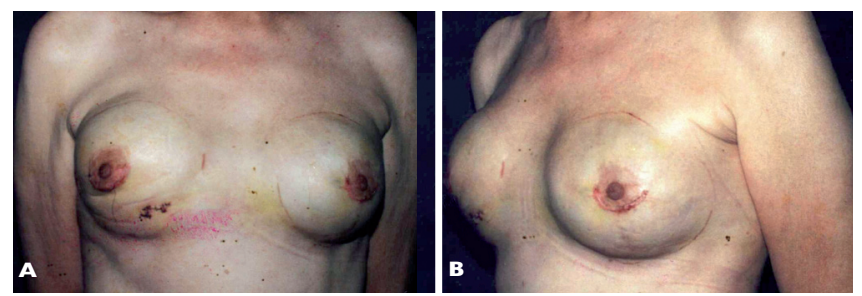

Figura 4 - Pós-operatório recente após o terceiro procedimento.

mamária, com especificações aplicadas a cada caso. Todas, porém, obedecem a um planejamento acurado, que visa reduzir ao máximo os efeitos secundários não desejáveis (Figura 4).

No caso descrito, apesar da contratura diversificada que determinou alterações da forma e volume das mamas, conseguimos simetrização de forma e volume dentro dos padrões ideais. Os critérios seguiram os preceitos das acomodações e da retração cutânea uniforme sobre o conteúdo de mesmo volume (Figura 5).

\section{CONCLUSÃO}

Apesar da maior simplicidade técnica no uso de implantes mamários em comparação às técnicas de retalhos cutâneos, e músculo cutâneos da vizinhança e/ou à distância nas reconstruções mamárias pós-adenomastectomias, as deformidades a médio e longo prazo ocorrem com alguma frequência. $\mathrm{O}$ objetivo deste estudo foi enfatizar a importância do planejamento correto para diminuir ou mesmo eliminar a possibilidade destes efeitos secundários.

\section{REFERÊNCIAS}

1. Badin J. Introdução à cirurgia plástica. Rio de Janeiro:Atheneu;1971.

2. Pitanguy I. Mamaplastia. Rio de Janeiro:Guanabara Koogan;1978.

3. Pitanguy I. Aesthetic plastic surgery of the head and body. New York: Springer-Verlag Berlin, Heidelberg; 1981.

4. Franco T. Princípios de cirurgia plástica. $1^{\mathrm{a}}$ ed. São Paulo:Atheneu;2002.

5. Baker Jr JL. Classification of spherical contractures. Presented at the Aesthetic Breast Symposium. Scottsdale, Arizona;1975.

6. Baker Jr JL, Bartels RJH, Douglas WM. Closed compression technique for rupturing a contracted capsule around a breast implant. Plast Reconstr Surg. 1976;58(2):137-41.
Correspondência para:
Luciano Alves da Silva

Rua Barão de São Borja, 254 - Boa Vista - Recife, PE, Brasil - CEP 50070-310

E-mail: news@cirurgiaplastica.org.br 